15. Харьковская Е.В., Мешков В.А. Роль эстетического воспитания студентов в образовательновоспитательном пространстве вуза // Наука. Искусство. Культура. 2014. № 4. С. 205-209.

16. Полонский В.М. Большой тематический словарь по образованию и педагогике. М.: Народное образование, 2017. $840 \mathrm{c}$.

17. Бездухов А.В., Лопухова Ю.В. Воспитание как движение, превращающее возможное в действительное // Известия РАО. 2011. № 1 (17). С. 66-75.
18. Кулюткин Ю.Н. Диалог как предмет педагогической рефлексии // Ценностные ориентиры и когнитивные структуры в деятельности учителя / Ю.Н. Кулюткин, В.П. Бездухов. Самара: СГПУ, 2002. C. 274-329.

19. Бездухов В.П. Теоретические проблемы становления гуманистического стиля педагогической деятельности будущего учителя. Самара: СамГПИ, 1992. $104 \mathrm{c}$.

\title{
THE UNITY OF MORAL AND AESTHETIC EDUCATION OF PROSPECTIVE TEACHER-DESIGNERS
}

(C) 2017

\author{
Statsenko Elena Rudolfovna, candidate of pedagogical sciences, \\ associate professor, head of Arts and Service Faculty \\ Murmansk Arctic State University (Murmansk, Russian Federation)
}

\begin{abstract}
In the paper the problem of university students' education is considered to be an urgent social and pedagogical problem. The authors think that it is important to combine moral, aesthetic, labor, physical, etc education in the educational process of a higher education institution. The importance of moral and ethical education of prospective teacher-designers is substantiated. The relationship between Good and Beauty is revealed as the value basis for moral and aesthetic education. Students' moral qualities development, their aesthetic tastes and ideals development correlates with the development of the value sphere of their consciousness. The process of university students' education is seen as their involvement in values. The authors prove that the unity of moral and aesthetic education of students - prospective teachers of design - is a complementary process of their involvement in moral and aesthetic values, when, regardless of a particular situation, moral values are meaningfully complemented by aesthetic ones while aesthetic values - by moral ones. The authors think that an effective means of moral and aesthetic education of university students is art as creative reflection, reproduction of reality in artistic images. The paper contains methods of moral and aesthetic education: talk, discussion, debate, ethical dialogue (classroom work); reading conference, viewing and subsequent analysis of movies, organizing amateur performances, excursions, etc. (extracurricular work).
\end{abstract}

Keywords: prospective teacher-designer; student; teacher; education; moral education; aesthetic education; unity; value; good; beauty; art; artistic image; method; values; classroom work; extracurricular work.

УдК 378.09

\section{ФОРМИРОВАНИЕ ЭКЗИСТЕНЦИАЛЬНЫХ АСПЕКТОВ ПРОФЕССИОНАЛЬНОЙ КОМПЕТЕНТНОСТИ БУДУЩИХ СОТРУДНИКОВ УГОЛОВНО-ИСПОЛНИТЕЛЬНОЙ СИСТЕМЫ}

(C) 2017

\author{
Тарасова Светлана Александровна, кандидат психологических наук, \\ доцент кафедры пенитенциарной психологии и педагогики \\ Самарский юридический институт ФСИН России (2. Самара, Российская Федераиия)
}

Аннотация. В статье обсуждается проблема профессиональной компетентности сотрудников уголовноисполнительной системы. Отмечается необходимость формирования у них готовности к трудностям на жизненном и профессиональном пути. Экзистенциальный аспект определяется как составная часть целостной профессиональной компетентности. В его содержание входит экзистенциальная установка по отношению к своей будущей профессиональной деятельности и жизни в целом. Экзистенциальная установка определяется как готовность будущего специалиста к саморазвитию и самосовершенствованию себя в качестве субъекта своей жизни и профессионального развития. В работе подчеркивается, что экзистенциальная установка выступает как духовный ресурс и способствует сохранению профессиональной вовлеченности будущего сотрудника уголовно-исполнительной системы в трудной жизненной ситуации. Отмечается, что экзистенциальная установка формируется в процессе развития рефлексии. В статье предлагаются формы учебной работы: экзистенциальный диалог, эссе, решение ситуационных задач. Дается краткая характеристика данных форм работы и приводятся конкретные примеры заданий. Называются показатели эффективности проводимой работы: появление у обучаемых интереса к духовной стороне жизни, к проблемам смысла жизни и профессиональной деятельности, ответственности за свой выбор.

Ключевые слова: профессиональная компетентность; профессиональная деятельность; экзистенциальные аспекты компетентности; уголовно-исполнительная система; экзистенциальная установка; субъект; рефлексия; профессиональная вовлеченность; экзистенциальный диалог; эссе; ситуационная задача; духовный ресурс; трудная жизненная ситуация; формы учебной работы. 
Профессиональной деятельности принадлежит существенное место в жизни человека. При этом роль профессии носит не только позитивный, но порой негативный и даже разрушительный характер по отношению к личности. По признанию специалистов, деятельность сотрудников уголовно-исполнительной системы - одна из наиболее деформирующих личность видов профессиональной деятельности. Многие сотрудники в своей работе со временем начинают руководствоваться антигуманными принципами, не умеют справляться с кризисными и конфликтными ситуациями, пребывают в состоянии хронического стресса, подвержены эмоциональному выгоранию.

Важным фактором в возникновении этих негативных явлений является то, что сотрудники часто бывают не готовы к трудностям, которые встретятся им на профессиональном пути. Профессиональный путь человека, как и жизненный в целом, представляет собой череду периодов подъема и спада, наполненных душевными переживаниями по поводу самореализации и самоутверждения, успехов или неудач, волнений, связанных с признанием или непризнанием. Для каждого человека в определенные периоды актуальны проблемы одиночества и непонимания, потери смысла профессиональной деятельности, невостребованности, а также дисгармоничного сочетания личной жизни и работы.

Чтобы выстоять перед натиском неблагоприятных обстоятельств и не «сломаться», будущему сотруднику уголовно-исполнительной системы необходимо быть готовым к трудностям на своем профессиональном пути. Для этого он должен не только обладать необходимыми знаниями, умениями и навыками в области конкретной профессии, но и получить психологическую подготовку в ее ценностносмысловом экзистенциальном аспекте. Целью нашей статьи является рассмотрение вопросов о содержании экзистенциального аспекта профессиональной подготовки будущих сотрудников УИС и методах его формирования в образовательном процессе вуза.

В Концепции модернизации российского образования определена основная цель профессионального образования - подготовка компетентного квалифицированного работника соответствующего уровня и профиля, конкурентоспособного на рынке труда, ответственного, свободно владеющего профессией и ориентированного в смежных областях деятельности [1]. Это гарантирует способность выпускника вуза к эффективной работе на уровне мировых стандартов, готового к постоянному профессиональному росту. Приоритетным направлением достижения этой цели в современных социально-экономических условиях является компетентностный подход, психолого-педагогической основой которого являются работы таких ученых, как В.Д. Шадриков [2], А.А. Вербицкий [3], И.А. Зимняя [4], В.С. Леднев [5], А.К. Маркова [6], Л.М. Митина [7], Э.Ф. Зеер [8], В.И. Байденко [9] и др.

С позиций компетентностного подхода уровень образованности в современных условиях определяется не столько объемом знаний, их энциклопедичностью, сколько способностью решать профессиональные проблемы и задачи различной сложности на основе имеющихся знаний. Сторонники компетент- ностного подхода провозгласили основой содержания образования не просто набор знаний, а более сложную культурно-дидактическую структуру - целостную компетентность. Под профессиональной компетентностью понимается интегральная характеристика личности, определяющая ее способность решать профессиональные проблемы и задачи с использованием знаний, умений, профессионального и жизненного опыта, ценностей и наклонностей. Следует обратить внимание на то, что образование при компетентностном подходе «работает» не только со знаниями и мышлением обучающихся, но и с их ценностями и смыслами. Это важно, поскольку ценности и ценностные ориентации, являясь основным структурным компонентом направленности личности, создают основу для принятия решений в ситуации выбора в различных профессиональных ситуациях.

Составной частью целостной компетентности будущего сотрудника уголовно-исполнительной системы является так называемый экзистенциальный аспект, под которым мы понимаем сформированную экзистенциальную установку по отношению к своей будущей профессиональной деятельности и жизни в целом. Впервые термин «экзистенциальная установка» ввел в научный оборот А. Лэнгле [10].

В нашей работе экзистенциальная установка определяется как готовность будущего специалиста к саморазвитию и самосовершенствованию себя в качестве субъекта своей жизни и профессионального развития. По мнению отечественных ученых, представителей субъектного подхода в психологии (С.Л. Рубинштейн [11], А.В. Брушлинский [12], К.А. Абульханова-Славская [13], В.В. Знаков [14], Л.И. Анциферова [15] и др.), субъект, в отличие от объекта социальной жизни, обладает свободой выбора, берет на себя ответственность за свое существование, судьбу, становление. Субъект - это человек, для которого важно найти свое, достойное место в жизни, иметь собственную позицию по отношению к быстро меняющимся условиям.

Экзистенциальная установка означает постоянную работу субъекта над осознанием собственной иерархии системы смысложизненных ориентаций, осмыслением и созданием концепции собственной жизни. Эта установка связана с развитием духовной составляющей человека, которая позволяет человеку понимать сущность жизненной ситуации и, опираясь на высшие ценности, конструктивно преодолевать жизненные трудности, действовать на основе осознанного и ответственно принятого решения. Экзистенциальная установка включает и формирование просоциальной направленности, альтруизм, определяет стремление субъекта быть полезным людям.

Экзистенциальная установка связана с профессиональной вовлеченностью - важнейшим фактором эффективности профессиональной деятельности. Эмоциональная и личностная вовлеченность определяется как особое состояние, характеризуется воодушевленностью и сопричастностью, внутренней мотивированностью. По мнению W. Schaufeli, это позитивное, приносящее удовлетворение состояние, которое характеризуется энергичностью, энтузиазмом и поглощенностью [16]. Экзистенциальная ус- 
тановка способствует сохранению профессиональной вовлеченности в трудной жизненной ситуации, поскольку субъект, обладающий зистенциальной установкой, «философски» относится к жизни, имеет духовную опору, дающую ему внутреннюю силу, спокойствие и уверенность в себе, возможность более осмысленно воспринимать ситуацию и выбирать конструктивные способы решения проблемы.

Экзистенциальная установка является результатом рефлексии - способности к самоанализу, к осмыслению своих действий и поступков, размышлению над экзистенциальными проблемами своей жизни и будущей профессиональной деятельности. Рефлексия направлена на понимание и познание своего духовного мира (высших целей, ценностей, смысла жизни, проблем своего существования, осознание свободы выбора, а также ответственности за принятые решения). От степени развития рефлексивных процессов зависит простота или сложность внутреннего мира субъекта, выбор и способ реализации жизненной стратегии. Благодаря рефлексии для субъекта возможен мысленный выход не только за пределы конкретной коммуникативной ситуации, но и за пределы собственной жизни, включение ее в какую-то иную систему координат, наделенную более значимым с точки зрения духовных ценностей смыслом.

Формирование экзистенциальной установки должно стать специальной задачей при подготовке будущих сотрудников уголовно-исполнительной системы, поскольку именно это качество, выступая в качестве духовного ресурса, позволит эффективно решать жизненные проблемы и противостоять трудностям.

При формировании экзистенциальной установки необходимо использование методов, которые обращены к внутреннему миру личности, глубинным истокам ее сознания, способствуют раскрытию истинных, сущностных, смысложизненных переживаний, отношений, позиций субъекта. К таким методам прежде всего относятся диалогичные методы обучения, имеющие экзистенциальный характер, т.е. являющиеся диалогами о высших целях, ценностях, смыслах жизни, судьбоносных проблемах существования человека [17]. Возникновение экзистенциальных диалогов между педагогом и обучающимися требует особых условий, в которых обсуждение проблем должно происходить не на поверхностном уровне, а существенно, открывая при этом путь для глубинной смысловой рефлексии. Экзистенциальный диалог - это диалог, осуществляющийся на уровне глубинных смыслов и предполагающий обмен духовной энергией. В ходе экзистенциальных диалогов особое внимание уделяется проблеме выбора субъекта в ситуации самоопределения. Выбор всегда связан с осознанием и реализацией собственного потенциала и определяется внутренней позицией личности, ее ценностными ориентациями [18].

Экзистенциальный диалог может быть элементом различных форм учебной работы, а может выступать как отдельная форма. Предлагаем следующие темы экзистенциальных диалогов:
Как выстоять перед лицуом неблагоприятных обстоятельств и не «сломаться»?

$B$ чем заключается ответственность сотрудника УИС?

Какое значение имеет такое свойство характера, как справедливость, для сотрудника УИС?

Как совместить личную жизнь и работу?

Обладает ли человек свободой выбора?

Что такое снобизм и нигилизм в профессии?

Как проявляются борьба мотивов и свобода выбора личности?

Что такое подвиг?

Зависит ли счастье человека от его будущего?

Что такое одиночество и как с ним бороться?

Можно предложить курсантам для обсуждения высказывания:

Природу человека лучше всего обнаружить в уединении, ибо он сбрасывает с себя показное; в порыве страсти, ибо тогда забывает он свои правила, а также в новых обстоятельствах, ибо здесь покидает его сила привычки (Ф. Бэкон).

Счастье вообще - вещь нелегкая: его очень трудно найти внутри себя и невозможно найти гденибудь в ином месте (М. Шамфор).

Нужно жить не для себя (эгоизм), не для других (альтруизм), а со всеми и для всех (Н.Ф. Федоров).

Также рекомендуем для выполнения такие задания:

Раскройте содержание понятий и укажите иенности, с ним связаннье: гедонизм, перфекционизм, эгоизм, альтруизм, конформизм.

Раскройте содержание понятия «манипуляциия. Подумайте, какие негативные последствия для личности имеет манипулятивный стиль поведения?

При формировании экзистенциальных аспектов профессиональной компетентности можно использовать и монологические формы учебной работы, например эссе. Эссе особенно эффективно в ракурсе экзистенциальной проблематики, так как позволяет обучаемому выразить то, что он не решился бы вслух сказать другому человеку. Эссе - небольшое письменное сочинение на определенную тему, в котором обучаемый рассуждает, выражает свою точку, анализирует какую-либо проблему. Оно посвящено анализу конкретной темы или вопроса и предполагает авторский взгляд на проблему, при этом не претендует на определяющую или исчерпывающую трактовку предмета. Это небольшое произведение может иметь философский характер, и в нем могут обсуждаться экзистенциальные проблемы. Темы эссе должны быть интересны обучаемым. Можно предложить следующие темы:

-Как я понимаю гуманизм?

- В чем смысл моей жизни?

- В чем моя индивидуальность?

- Что такое любовь как иенность?

- Как я понимаю понятие «справедливость»?

- Что такое лень и как с ней бороться?

- Почему я выбрал эту профессию?

- Как я отношусь к осужденным?

- К чему я стремлюсь в профессии?

Для формирования экзистенциальной установки у обучаемых можно использовать разнообразные хо- 
рошо известные формы работы: решение ситуационных задач, дискуссии, просмотр кинофильмов или документальных фильмов с последующим их обсуждением и др. Ситуационные задачи направлены на анализ и интерпретацию ситуации, оценивание действий ее участников, прогнозирование ее развития, выбор адекватных способов решения. Решение ситуационных задач может осуществляться в процессе группового анализа, основные элементы которого мы приводим [19].

1 Знакомство с проблемой.

Преподаватель делает краткое вступление, называя тему предстоящей работы и ее цель, и предлагает конкретную ситуацию, которая послужит предметом группового анализа.

2. Сбор банка решений.

На этом этапе собираются разные варианты решения проблемы. Затем решения классифицируются, выявляются наиболее типичные из них.

3. Обсуждение и сравнительный анализ предложенных вариантов решения ситуации.

Преподаватель должен внести критерии оценки действий участников обсуждаемой ситуации.

4. Обобщение результатов анализа ситуации, выводы.

На этом этапе выбирается наиболее эффективное решение задачи. Формулируется более общая экзистенциальная проблема, ярким конкретным проявлением которой становится описанная ситуация. Ocознание и принятие общей проблемы учащимися, рассмотрение ее в различных плоскостях психологического анализа позволяет сделать шаг к большей профессиональной компетентности в экзистенциальном аспекте.

Примеры ситуационных задач.

Задача 1 [20]. В колонию общего режима на работу в должности начальника отряда поступил выпускник юридического вуза Н. Сидоров. Молодой человек отличался невыразительной, скромной внешностью - невысок ростом, худощавого телосложения. Когда в первый раз Сидоров вышел перед строем осужденных, кто-то выкрикнул: «Обрезок!». Раздался дружный смех. Начальник отряда не нашелся, что ответить, смутился и покраснел. Грубая кличка сразу закрепилась за новым начальником отряда. Сидоров сильно переживал по поводу произошедшего инцидента. У него появились признаки депрессии. Вскоре начальник отряда Сидоров подал рапорт об увольнении.

1. Проанализируйте ситуацию с психологической точки зрения.

2. Как следовало бы поступить новому начальнику отряда в данном случае?

3. Каковы действия начальника колонии?

Задача 2. Никифоров Сергей перевелся из колонии А в колонию Б в связи с переездом из другого города и устроился на должность сотрудника оперативного отдела. С первых дней Сергей энергично взялся за дело. Всем было видно, что это неравнодушный и заинтересованный в работе человек. Руководители часто хвалили Сергея на общих собраниях, и в коллективе начали поговаривать о его скором повышении в должности. Однако нашлись завистники, которым было не выгодно продвижение Никифорова вверх по служебной лестнице. Коллеги стали распространять нелепые слухи о внеслужебных связях Сергея с осужденными, жаловаться на его неуживчивость и конфликтность. Сначала Сергей ни о чем не догадывался, но вскоре заметил, как изменилось отношение к нему со стороны коллектива и руководства. Потом началась откровенная травля. Сергей из уважаемых сотрудников перешел в категорию тех, кого вечно за что-то ругают. Сергей сильно переживал по поводу сложившейся ситуации. Он не мог понять, почему люди верят клевете и закрывают глаза на его добросовестное отношение к работе и профессионализм. Сергею все чаще приходили в голову мысли об увольнении, но сделать это он не мог, так как надежную работу в маленьком городке найти сложно.

Вопрос: Проанализируйте ситуачию. Как бы вы поступили на месте Сергея Никифорова?

Об эффективности работы по формированию экзистенциальной установки можно судить, если у курсантов усилилось желание учиться в выбранном направлении, по выбранной специальности, будущая профессиональная деятельность наполнилось большим смыслом и появилось понимание того, что в ней есть возможность самореализоваться, если возникло желание разобраться в личностно значимых проблемах, понять их причины, если усилился интерес к духовной стороне жизни, если возникло осознание ответственности за свой выбор.

Таким образом, формирование экзистенциальных аспектов профессиональной деятельности будущих сотрудников уголовно-исполнительной системы видится нам как формирование экзистенциальной установки, под которой понимается готовность будущего сотрудника к саморазвитию и самосовершенствованию себя как субъекта своей жизни и профессионального развития. Это возможно в процессе развития рефлексии - способности осмысливать свои действия и поступки, размышлять над экзистенциальными проблемами своей жизни и будущей профессиональной деятельности, формировать собственную мировоззренческую и профессиональную позицию. В данном случае эффективны диалогические формы обучения, позволяющие осуществить позитивное взаимодействие на уровне смыслов, обмен духовной энергией, и монологические, способствующие глубинной смысловой рефлексии.

\section{СПИСОК ЛИТЕРАТУРЫ:}

1 Концепция Федеральной целевой программы развития образования на 2016-2020 гг. Распоряжение Правительства Российской Федерации от 29.12.14 № 2765-p.

2. Методика оценки уровня квалификации педагогических работников / под ред. В.Д. Шадрикова, И.В. Кузнецовой. М., 2010. [Электронный ресурс] // https://portal.iv-edu.ru.

3. Вербицкий А.А., Ильязова М.Д. Инварианты профессионализма: проблемы формирования: монография. М.: Логос, 2011. 288 с.

4. Зимняя И.А. Ключевые компетентности как результативно-целевая основа компетентностного подхода в образовании. Авторская версия. М.: Исследовательский центр проблем качества подготовки специалистов, 2004. 40 с. 
5. Леднёв В.С. Содержание образования: сущность, структура, перспективы. 2-е перераб. изд. М.: Высшая школа, 1991. 223 с.

6. Маркова А.К. Психология профессионализма. М.: Международный гуманитарный фонд «Знание», 1996. 312 c.

7. Митина Л.М. Психология труда и профессионального развития учителя. М.: Академия, 2004. 320 с.

8. Зеер Э.Ф. Психология профессий: учебное пособие для студентов вузов. 2-е изд., перераб., доп. М.: Академический Проект; Екатеринбург: Деловая книга, 2003. $336 \mathrm{c.}$

9. Байденко В.И. Компетенции в профессиональном образовании (к освоению компетентностного подхода) // Высшее образование в России. 2004. № 11. С. 3-13.

10. Лэнгле А. Эмоциональное выгорание с точки зрения экзистенциального анализа // Вопросы психологии. 2008. № 2. С. 3-16.

11. Рубинштейн С.Л. Бытие и сознание. Человек и мир. СПб.: Питер, 2003. 512 с.

12. Брушлинский А.А. Психология субъекта. М.: Институт психологии РАН, СПб.: Алетейя, 2003. 272 c.

13. Абульханова К.А. Психология и сознание личности. М., Воронеж, 1999. 224 с.
14. Знаков В.В. Психология субъекта как методология понимания человеческого бытия. Психологический журнал. 2003. Т. 24, № 2. С. 95-106.

15. Анциферова Л.И. Психология формирования и развития личности // Психология личности в трудах отечественных психологов. СПб., 2001.

16. Полунина О.В. Взаимосвязь увлеченности работой и профессионального выгорания (на примере представителей сферы обслуживания): дис. ... канд. псих. наук. М., 2009. 213 с.

17. Шоган Е.В. Экзистенциальные диалоги как фактор ценностно-смыслового развития личности старшеклассника в образовательном пространстве школы: дис. ... канд. псих. наук. Ростов-на-Дону, 2006. $230 \mathrm{c}$.

18. Мухина В.С. Возрастная психология. Феноменология развития: учебник для студ. высш. учеб. заведений. 10-е изд., перераб. и доп. М.: Академия, 2006. 608 c

19. Турусова О.В. Психология в вопросах, задачах и упражнениях: учебное пособие. Самара: Издательство Самарского университета, 1994. 406 с.

20. Тарасова С.А. Психология сотрудников УИС: личность, общение, деятельность: учебное пособие. Самара: Самарский юридический институт ФСИН России, 2007. 114 с.

\title{
DEVELOPMENT OF EXISTENTIAL ASPECTS OF PROFESSIONAL COMPETENCE OF PENITENTIARY SYSTEM PROSPECTIVE EMPLOYEES
}

(C) 2017

Tarasova Svetlana Alexandrovna, candidate of psychological sciences, associate professor of Penitentiary Psychology and Pedagogy Department Samara Law Institute of the Federal Penitentiary Service of Russia (Samara, Russian Federation)

Abstract. The paper discusses the problem of professional competence of penitentiary system employees. The author says that employees of the penal system should be ready for the challenges of the vital and professional way. The author defines existential aspect as part of holistic professional competence. Existential setting is included in the existential aspect of professional competence. Existential setting is defined as readiness of a future specialist for selfdevelopment and self-improvement. Existential setting is a spiritual resource of a person. Existential setting helps to maintain interest in the professional activity of penitentiary system employee in difficult situations. Existential setting is formed in the process of reflection development. The paper considers forms of educational work: existential dialogue, essays, solution of situational problems. The author gives a brief description of these forms of work and specific examples. The paper contains indicators of effectiveness: students' interest in the spiritual side of life as well as in problems of the meaning of life and professional activities.

Keywords: professional competence; professional activities; existential aspects of competence; penal system; existential attitude; subject; reflection; professional engagement; existential dialogue; essay; situational problems; existential resources; difficult life situations; forms of educational work.

УДК 378

\section{МЕЖДИСЦИПЛИНАРНАЯ ИНТЕГРАЦИЯ КАК МЕТОД ОБЕСПЕЧЕНИЯ ВЫСОКОЙ ИНТЕНСИВНОСТИ ОБУЧЕНИЯ ОДАРЕННЫХ ОБУЧАЮЩИХСЯ} (C) 2017

\author{
Тимощук Нина Александровна, кандидат филологических наук, доцент, \\ заведующий кафедрой психологии и педагогики \\ Михелькевич Валентин Николаевич, доктор технических наук, \\ профессор кафедры психологии и педагогики \\ Рябинова Елена Николаевна, доктор педагогических наук, \\ профессор кафедры высшей математики и прикладной информатики \\ Самарский государственный технический университет (2. Самара, Российская Федеращия)
}

Аннотация. В статье показано, что наряду с акцентированием значимости приоритета привлечения твор-
чески одаренной молодежи к научно-исследовательской деятельности в направлениях работы государствен-
ных и губернских структур Самарской области, в региональной Единой системе мер по выявлению и разви- 